
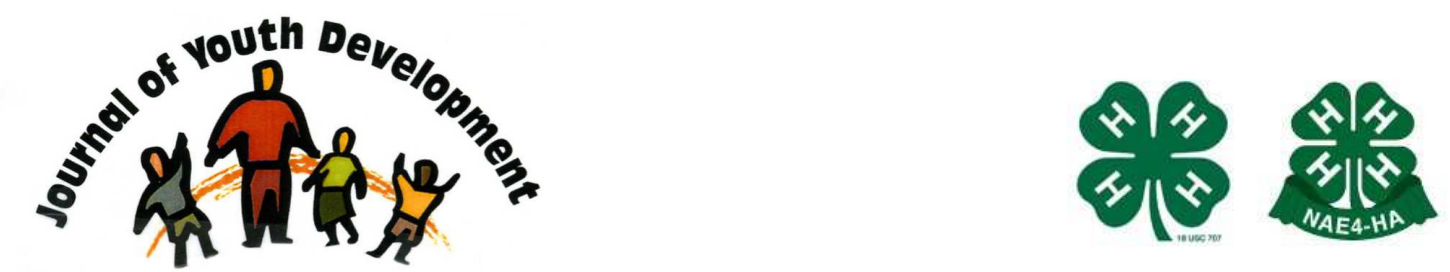

Bridging Research \& Practice

\title{
Without Television
}

Keri A. Schwab

California Polytechnic State University

San Luis Obispo, CA

keschwab@calpoly.edu

Barbara Brock

Eastern Washington University 


\title{
JOURNAL OF YOUTH DEVELOPMENT \\ bridging research and practice

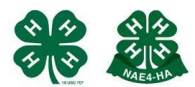

Volume 9, Number 1, Special Edition 2014

Article 140901FA007

\section{Without Television}

\author{
Keri A. Schwab \\ California Polytechnic State University \\ Barbara Brock \\ Eastern Washington University
}

"At this point in my life, the trail goes where I make it go - or perhaps where I let it run" An exploratory follow-up study of the leisure choices of youth who grew up without television.

\begin{abstract}
The purpose of this follow-up study was to learn more about the leisure choices, hobbies, and lifestyles of young adults who had grown up without a television. Study participants responded to an online questionnaire that asked about their health, physical activity habits, hobbies, and level of current television viewing. A mixed methods approach to gathering and analyzing data revealed a picture of young adults who live active lives, watch little television, and appear to have a strong sense of personal agency to direct their lives. Themes of agency, including forethought and intentionality, and self-regulation were evident in the qualitative responses, as well as creation and choosing challenging hobbies or activities. This study provided much information for future research to examine the influence of television on youth development, specifically agency, challenge and life-long habits.
\end{abstract}

\section{Introduction}

Television viewing among American children has steadily increased during the first decade of the $21^{\text {st }}$ Century with youth ages two to 18 watching as much as 4.5 hours per day, or a high of almost 32 hours per week in 2009 (Child Trends Data Bank, 2009; Nielson 2009). Among this group, researchers have also noted various health or academic trends such as an increased sedentary behaviors, consumption of unhealthy snack foods, and body fat, (Carson, \& Janssen, 2012; Gorley, Marshal, \& Biddle, 2004). While not causal indicators, the correlational data indicating negative outcomes among those who spend much time in front of the television is certainly compelling. What then, might life look like for youth who spent little to no time in front of the television? 
In the late 1990s, author, researcher and leisure studies professor Barbara Brock sought to answer this question. Having raised her own children without a television in the home, she was interested in learning more about the choices and lifestyles of families who lived without television. Between 2000 and 2001, Brock conducted a survey asking about the lifestyles, social interactions, community involvement, and decision to go TV-free of some 500 families, with more than 1,200 individual responses from parents and children. The 100-item questionnaire generated enough data for Brock to publish a book, Living Outside the Box: TV Free Families Share their Secrets, in 2006. The results indicated that families without television were more involved in their communities, had stronger bonds with one another, lived active lifestyles, had a variety of unique hobbies, and did not feel they were missing anything by disconnecting from modern media outlets (Brock, 2007).

A decade later, Brock realized that youth in the initial study would now be college or young adult age. Knowing the purported harmful effects of television viewing on youth, Brock decided to inquire as to the longer term impacts of not having a television. She wanted to know more about the attitudes, leisure activities, and health and academic outcomes of youth who grew up without television, now that they were young adults. And if this group reported anything notable as related to important youth outcomes, different than the average television-viewing young adult, future research could examine to what extent television played a role.

The purpose of the current study, then, was to find and follow up with youth from the initial study to gather a picture of their lifestyles, hobbies, and choices after having grown up without television.

\section{Study Aims}

The purpose of this preliminary follow up study was to learn about, in a mixed-methods format, the choices, lifestyles, habits, and attitudes of youth who grew up without television, and use that information to develop further questions on this topic. The young adults who participated in this follow up study were those who had grown up in homes without a television, per their parents' decision. Data gathered in the quantitative portion of the study included information about overall health, smoking or alcoholic beverage consumption, level of physical activity, body weight estimation, and hours spent outside, volunteering, and reading. Qualitative or openended questions asked participants if they still limit television viewing now, and if so, why, and to describe their hobbies and plans for the future.

\section{Sample}

For the 2001 study, Brock interviewed families who either did not own a television, or if they did, watched it a minimum of one hour per week. The purpose of the initial study was to learn more about parents' decision to limit viewing, and to learn about the lifestyles, habits, and hobbies of this group. To find an initial group of respondents, Brock placed ads in three magazines or similar publications targeted at families. More than 500 families responded, and were invited to complete a 100 -item web-based questionnaire. Brock ultimately collected data from 1,500 individuals, and ultimately published her book. After the books' publication, however, Brock lost direct contact with many of the family members.

To conduct this follow up survey, Brock took several steps. First, she mailed a letter explaining the 10-year follow up study to each of the original participating families, using the addresses she had for them from 2001. She asked the parents to forward the letter to their now-grown 
children, who were then invited to participate in a web-based survey. After many returned envelopes, the final sample resulted in 53 respondents. The majority of young adults ranged in age from 15-24 years old, lived in 23 states, and indicated they had either completed college $(26 \%)$ or had a Master's degree (15\%). Selected demographics are presented in Table 1.

\section{Methods}

An online questionnaire consisting of 80 closed and opened ended questions was available to respondents for three months. Questions were closed ended (multiple choice), and openedended, to which participants could type as much as they chose. Some open-ended questions were as follow-up to closed-ended questions, others were unique questions on their own. To complete the online questionnaire, participants received by email or paper mail the address of an electronic link, and once accessed, the initial page contained an introduction and instructions, followed by several pages of questions separated into five categories including demographics, lifestyle, technology use and habits, community life, and aspirations and advice.

Table 1

Selected demographic data of respondents in follow-up study

\begin{tabular}{|l|l|l|}
\hline Age Range & $15-19$ years old & $38 \%$ \\
\hline & $20-24$ years old & $21 \%$ \\
\hline & $25-29$ years old & $19 \%$ \\
\hline Level of Education & & \\
\hline & Some High School & $24 \%$ \\
\hline & GED & $10 \%$ \\
\hline & Some College & $19.6 \%$ \\
\hline & Bachelor's Degree & $26 \%$ \\
\hline Race & Master's Degree & $15 \%$ \\
\hline & & \\
\hline Sex & White & $85 \%$ \\
\hline & Asian American & $4 \%$ \\
\hline Marital Status & & \\
\hline & Male/Female & $43 \% / 57 \%$ \\
\hline & & \\
\hline & Single & $78 \%$ \\
\hline Job Status & Married & $15 \%$ \\
\hline & Cohabitating & $4 \%$ \\
\hline & & \\
\hline & Student & $53 \%$ \\
\hline & Full-time employment & $34 \%$ \\
\hline & Part time employment & $8.5 \%$ \\
\hline
\end{tabular}

All responses were anonymous, however if participants wanted to receive a free copy of Brock's first book, they were asked to provide a mailing address. Once the survey period closed, the data were downloaded and compiled in an electronic format for analysis by the researchers. 


\section{Data Analysis}

For this mixed methods study, data were separated into quantitative and qualitative results and analyzed separately. Quantitative data consisted of descriptive statistics only and are reported as such in tables 1,2 and 3.

The qualitative portion of this study was analyzed using a grounded theory approach. Grounded theory, according to Charmez (2006), is an "inductive, comparative, iterative, and interactive method" (p. 347). In this data analysis process, researchers move from looking at the concrete stories or realities expressed in the data to more conceptual understandings of the data. The analysis is an ongoing, iterative process in which researchers move back and forth between the data and relevant literature to look for plausible connections (p. 347).

In addition, while conducting the qualitative data analysis, the researchers engaged in memoing, or the process of writing notes and connecting ideas as they read and re-read the data. The researchers worked separately at first, then together, to memo as they read the data, noted ideas, themes, and connections, and then compared memos. Then, as is part of grounded theory development, the researchers looked for conceptual relationships among themes, especially noting relationships linked by participants themselves. Finally, the researchers examined the data for thematic patterns in participant responses, and noted how the patterns related to the process under question (Strauss, \& Corbin, n.d.).

\section{Results}

The results are separated into quantitative and qualitative, with the quantitative further describing the population, and the qualitative describing themes that emerged from participant responses to open-ended questions.

\section{Quantitative Results}

The quantitative results are reported in the form of tables separated by the topics of health and leisure time activities. Only descriptive statistics are reported, and no further data analyses were conducted. A discussion of the quantitative results follows in the next section.

Table 2

Selected Health Data

\begin{tabular}{|l|l|l|}
\hline Smoker & Yes/No & $0 \% / 100 \%$ \\
\hline Drink alcohol? & Yes/No & $40 \% / 60 \%$ \\
\hline Time Spent Outside Daily & & \\
\hline & 2 hours or more & $21 \%$ \\
\hline & $1-2$ hours & $21 \%$ \\
\hline & $30-60$ minutes & $30 \%$ \\
\hline & $15-30$ minutes & $17 \%$ \\
\hline Time in Physical Activity (daily) & & \\
\hline & $1-2$ hours & $28 \%$ \\
\hline & $30-60$ minutes & $45 \%$ \\
\hline & $15-30$ minutes & $13 \%$ \\
\hline & $\begin{array}{l}\text { Less than } 15 \\
\text { minutes }\end{array}$ & $4 \%$ \\
\hline
\end{tabular}




\section{Qualitative Results}

The main theme that emerged from memoing and the grounded theory analysis process was respondents' sense of personal agency, or desire and ability to control, direct, and choose a course of action in their lives. One subcategory that emerged from that theme described what the young adults enjoyed doing, mainly creating, designing, or making things. These themes are explained further and linked to relevant literature.

Table 3

Leisure Time-Use Data

\begin{tabular}{|c|c|c|}
\hline \multicolumn{3}{|l|}{ Current Television Viewing } \\
\hline & 1-2 hours each day & $8.5 \%$ \\
\hline & Less than one hour daily & $42 \%$ \\
\hline & None & $44 \%$ \\
\hline \multicolumn{3}{|l|}{ Leisure Time Use-Computers } \\
\hline & 1-2 hours each day & $36 \%$ \\
\hline & $30-60$ minutes & $25 \%$ \\
\hline & $15-30$ minutes & $6 \%$ \\
\hline & Less than 15 minutes & $8.5 \%$ \\
\hline \multicolumn{3}{|l|}{ Leisure Time Use- Phones } \\
\hline & $2-4$ hours & $11 \%$ \\
\hline & 1-2 hours & $6 \%$ \\
\hline & $30-60$ minutes & $15 \%$ \\
\hline & $15-30$ minutes & $21 \%$ \\
\hline & Less than 15 minutes & $25 \%$ \\
\hline & None & $17 \%$ \\
\hline \multicolumn{3}{|l|}{ Time spent reading each day } \\
\hline & More than 2 hours & $13 \%$ \\
\hline & 1-2 hours & $34 \%$ \\
\hline & $30-60$ minutes & $30 \%$ \\
\hline & $15-30$ minutes & $17 \%$ \\
\hline & Less than 15 minutes & $6 \%$ \\
\hline \multicolumn{3}{|l|}{ Time spent on hobbies } \\
\hline & 2 hours or more & $31 \%$ \\
\hline & 1-2 hours & $36 \%$ \\
\hline & $30-60$ minutes & $18 \%$ \\
\hline & $15-30$ minutes & $9 \%$ \\
\hline
\end{tabular}

\section{Personal Agency}

This theme emerged largely from the question "what motivates you to continue to limit your television viewing today," and a common response was that participants desired to spend their time engaged in more interesting and self-directed activities. A response that best illustrates this theme is the person who limits television viewing because, "I am out of the house most of the time for teaching, and building my creative career takes time when I am at home." In linking this theme to the literature, there is a similarity with Bandura's idea of personal agency, or the idea that an individual can influence their behavior and outcomes. Respondent comments 
that further elucidate this theme are included below, but first, the idea of agency as suggested in this study, is explored.

Bandura (2006) wrote that humans are "self-organizing, proactive, self-regulating, and selfreflecting. They are not simply onlookers of their behavior. They are contributors to their life circumstances, not just products of them," (p. 164). In defining personal agency, Bandura suggests four main properties, all of which are further represented in the experiences described by study respondents. The properties include intentionality, forethought, self-reactiveness, and self-reflectiveness. Briefly, intentionality is the ability to make plans and turn them into reality, forethought is planning or thinking about the future, often by setting goals and anticipating desired outcomes, and self-reactiveness is when one can motivate or regulate behavior in pursuit of goals. Finally, self-reflectiveness, or self-awareness, is the ability to reflect on one's own thoughts, actions, and direction, and change course if necessary (Bandura, 2006). These four properties can be heard in the young adults' responses, as their stories suggest that many have desired goals and outcomes, a plan to achieve them, and an ability to regulate and reflect on their behavior in order to reach their goals.

Intentionality and forethought. Creating and acting on an action plan characterizes intentionality and forethought as two properties of personal agency. Respondents in this study were asked about their leisure time and television viewing choices, thus their examples of agency relate to those behaviors.

When discussing if they did watch television, and what they watched, the comments well illustrate properties of forethought and intentionality. For example, several respondents indicated that when they watched television, it was on their terms - they chose when, how, and why. For example, one said, "I can watch all the shows that I like on Netflix without being constrained by schedules," and another wrote, "I don't like trying to arrange my schedule around when new episodes will be showing." Other respondents said they only watched select shows - either on TV or online; "The Internet gives me my Daily Show and the like," wrote one, and another, "I will watch TV for events, like the Olympics or the World Cup." Another young woman wrote that she and her ex-boyfriend used to "always use Netflix or Hulu to watch TV shows and movies because we didn't have the time or patience to watch so many commercials." Knowing what they want to watch, and creating and following through with a plan to watch those shows demonstrates intentionality and forethought, components of a sense of personal agency.

Self-Reactiveness and self-reflectiveness. Self-reactiveness is the ability to regulate or control behavior in order to better achieve goals, while self-reflectiveness is metacognition - or the ability to think about the thinking. Self-reactiveness (or regulation) was evident among the respondents as many wrote about adjusting television viewing habits in order to facilitate goal achievement. Put simply, one person wrote, "TV takes up time and is a distraction from the work I have to get done on a daily basis." Other respondents were more specific in their reasons for self-regulating television viewing to prevent interference with goal attainment. One person wrote that television viewing was a "distraction between God and other close relationships that I hold." In this ability to control behavior, the young adults demonstrated an additional property of agency. Finally, self-reflectiveness is a metacognitive skill - or thinking about ones thinking process - and was not specifically asked of participants in this study. 


\section{Creation}

In this study, a subtheme of agency emerged - that of creation. When the young adults were asked about their leisure-time activities, the hobbies they listed and described included unique and diverse activities, and most involved creation or design. For example, specific hobbies listed included; "the French language," "I make my own props," "making weapons out of Legos," "raising chickens," "extra (advanced) math program as hobbies...(this list) grows as I learn about and try new things," "jewelry making," "self-propelled band," "sewing clothes, stuffed animals, and costumes," and finally, a few people wrote "making things" and "being creative."

The majority hobbies listed were not cognitively simple tasks or sedentary activities, but rather most required the person to create, think, design, or learn something new in order to sustain the hobby. Creation is often listed as an indicator of a cognitive higher order thinking skill under synthesis in the original Bloom's Taxonomy of Educational Objectives (Bloom, 1956). When a person creates, or synthesizes information, they bring together multiple ideas or materials to form something new. In recent years, Bloom's taxonomy underwent an update to better reflect current ideas and research on educational objectives. Several changes were made to a 2001 revised version, and most relevant to this study was the change of synthesis to create, and its relocation to the very top of the pyramid. In this revised taxonomy, creation is defined as when a person puts "elements together to form a novel, coherent whole or make an original product," and can be described with verbs such as plan, generate, or produce (Krathwohl, 2002, p. 215). Its placement at the top indicates the importance of creation as the most desirable outcome of an education. Creation also appears in the psychomotor and affective domains of Bloom's taxonomy, examples of which might include operating a self-propelled band (as one respondent does), or an affective creation, such as creating a personal values system. To create is a goal of education and, in general, an important thinking skill.

To sum up a sense of personal agency and creation for her family, one mother offered this statement; "I'd rather my kids, my spouse and I to be doing things than sitting around watching all the time. I want our family to be active and engaged with each other." What is notable is that, presumably, while the young adults are not watching television they have had more time to pursue a variety of creative activities. Depending on how they use their ability to synthesize and create, or depending on their own metacognitive abilities, the ability to create may or may not have impact in other areas of their lives, such as school, work, or solving other real-world problems.

\section{Discussion}

The purpose of this ten-year follow-up study was to find out about the lives, habits, and choices of young adults who had grown up without television. Questions for the young adults included if they still limited their television viewing, why, and what other leisure time activities they engaged in. Overall, study results paint a picture of people who watch less television than their peers, have better health habits, and who expressed a sense of personal agency to plan, direct, and take action to achieve their life goals, often by self-limiting television viewing.

These results are interesting for a number of reasons and provide avenues of exploration for future research into the impact of media on youth development. The discussion section is divided into two parts; a consideration of health outcomes and a discussion of personal agency and what these may mean for youth development. 


\section{Television Viewing and Health Indicators}

The young adults in this study indicated healthier lifestyles and habits than their average American counterparts. There could be several reasons that may relate to not watching television as youth, or could relate to their general household environment, parenting style, or influence of peers. This discussion will focus on the potential link between television viewing and health outcomes.

In looking at the quantitative data, some general comparisons can be made between this responding group and national averages. Comparisons can be made between hours of television viewing, body weight, and data provide indicators of time spent outside, and physical activity. Comparisons made are between data from this study and that reported by the Centers for Disease Control (CDC, 2010) National Center for Health Statistics, with data reported for several two and three year time frames. Because the age groupings used in this study are not the same as the CDC, direct comparisons cannot be made for the descriptive statistics reported here, however, enough similarities exist to be of interest for future research.

Health indicators. These are several health-related statistics reported in the results section, and this section will look at comparisons and correlations among between television viewing and physical activity, obesity, and smoking.

First, young adults in this study reported much less television viewing than the average American in their age range. According to Nielsen (2009), young adults age 18-24 spend 21 hours and 59 minutes each week watching television - or an average of 3.08 hours per day. In contrast, $44 \%$ of respondents in this study reported watching no television, or less than one hour per day (42\%). As noted in the literature review, increased television viewing is often correlated with a decline in health and academic outcomes. By not watching much television, this study's respondents may be on a path to improved health outcomes.

Second, respondents indicated lower weight and more physically active time, and time outside than the average American in a similar age range. In the study of TV-free young adults, the only question related to weight asked if respondents were more than ten pounds overweight. Only $13 \%$ reported they were, indicating that this group likely has a lower BMI or risk for overweight or obesity than the general population. In comparison, the CDC reported that during $2007-2010,18 \%$ of youth ages $12-19$ had a BMI in the $95^{\text {th }}$ percentile, qualifying them as obese. While this is not a direct comparison, the percent of overweight or obese youth is higher in the national sample. In another health indicator, $40 \%$ of youth in the current study reported spending 30-60 minutes engaged in physical activity each day, or anywhere from 210- 240 minutes per week. Again, direct comparison cannot be drawn, but to glimpse the national average, the CDC reports that about $55 \%$ of $18-24$ year olds participate in at least 150 minutes of moderate to vigorous activity each week. Finally, $21 \%$ of the non-television viewing respondents spend 2 or more hours outside each day, and $21 \%$ spend $1-2$ hours. Comparable national data is not available, but overall these data paint a picture of youth with physically active lifestyles and may be in better health than their average American counterpart.

Future research on television-free youth could collect data to compare to national averages, as well as ask why TV-free youth may have healthier lifestyles, if that is indeed the case. Here, we suggest a few reasons why television-free youth may have healthier lifestyles, and provide avenues for future research. One obvious connection is that youth who do not watch television are less likely to be sedentary. Young adults in this study expressed participation in hobbies that were physically active or at least required more movement than the act of sitting to watch 
television. Youth who grew up not watching television may have developed from an early age a lifestyle of leisure time physical activity. This could perhaps be a reason for their lower reported body weight and increased time spent outside or in physical activity.

Another reason respondents in this study might report healthier weight could be because they were not influenced by food and drink advertisements. Commercials for fast food and sugary snacks or drinks are prevalent on television, especially during shows targeted at children. A report on children's television viewing stated that children ages 8-12 years old view 21 food advertisements each day, and one-third of those are for candy and snacks, a quarter for cereal, and one-tenth for fast food (Gantz, Schwartz, Angelini, \& Rideout, 2007). Further, researchers have noted positive correlations between fast food consumption and television/video viewing time among preschool children (Taveras, Sandora, Shih, Rosss-Degnan, Goldmann, \& Gillman, 2006), and among older children and adolescents (Boynton-Jarrett, Thomas, Peterson, Wiecha, Sobol, \& Gortmaker, 2003). Other researchers have suggested that "reducing television viewing could affect energy (calorie) intake by minimizing cues to eat and by decreasing exposure to television advertising," (Epstein, Roemmich, Robinson, Paluch, Winiewicz, Fuerch, \& Robinson, 2008). Future research could further investigate the health attitudes and habits of children who grew up without the influence of television advertisements.

What the health-related responses from this study suggest is that, perhaps in the absence of television, youth or young adults develop physically active hobbies, and are not influenced by marketing and media images, which could lead to healthier lifestyle choices. Coupled with the sense of personal agency also suggested among this group, we see a group of people who have grown up and developed a healthy, active, self-directed lifestyle. Rather than passively view television or accept what it presents as an activity or hobby, young adults may have taken other avenues to develop and form lifelong creative and healthier habits. This is not to say that those who watch television are not capable of doing this, they may be, but among youth without television, the idea of personal agency and creation were certainly dominant in their narratives.

The idea that perhaps television viewing leads to a more passive lifestyle, and the consideration that without television one might have a more engaged or active lifestyle, is also suggested in the literature by Kubey and Csikszentmihalyi (1990), and is discussed in the next section.

\section{Television Viewing, Order, and Pleasure}

The idea that individuals who do not watch television may live a more active or engaged lifestyle is also suggested by research on people who do watch television. In a book about daily life experience and television viewing, researchers Kubey and Csikszentmihalyi (1990) gathered hundreds of reports via the experience sampling method from American television viewers. In short, they found that television viewers had often felt unsatisfied by their viewing, and reported low affect and cognitive activation. The researchers offer an explanation as to why television viewing is less satisfying, and then suggest activities that are more satisfying. Interestingly, the hobbies engaged in by television-free young adults have the same properties as activities Kubey and Csikszentmihalyi report as satisfying. Those properties include a human need to have order in, or make sense of experiences, and a human urge to seek pleasure in everyday life.

In the case of television viewers, structured, organized television programs give order to the information without much effort on the part of the viewer, meeting the first need. Then, the visual medium provides a low-challenge environment in which to relax physically and cognitively, thus meeting the human need for pleasure. As these needs are met with relative 
ease, the viewer may be drawn to watch more television in a habitual or almost addictive manner to continue to find relaxation or pleasure, and satisfy human needs.

In contrast, when we look at hobbies engaged in by non-television viewers, the same human needs for order and pleasure are met, but in very different ways. When engaged in creative hobbies or challenging tasks, humans in general often report being in a state of flow, characterized by a balance of challenge and skill in an activity, and often described as a sense of heightened awareness, deep involvement, increased mental effort and focus (Kubey \& Csikszentmihalyi, 1990, p. 141). Because challenge and skill are balanced, the hobby or activity requires mental ordering or organization, thus meeting this human need. Then, when the task is completed or the person feels success, they experience pleasure in their accomplishment, meeting another human need. These feelings, organization and pleasure, are continuous human needs, but in order to be met via hobby or activity, challenge and skill must increase in order for flow to occur. In this way, those constantly seeking flow are also working toward a life of "personal growth and learning because to keep experiencing it, one needs to continue to challenge oneself and to do this, one must keep developing greater skills." (Kubey, \& Csikszentmihalyi, 1990, p. 142).

Overall, then, the question to consider is of what importance is agency and creativity in youth development in the modern society, and to what extent does television viewing impact agency, creativity, or the desire to seek flow by increasing challenge and skills? While there are certainly other social and environmental influences on youth agency, from the experiences shared in this study, one plausible connection may be that the absence of television in a child's life can impact health habits, pursuit of creative hobbies, and development of personal agency.

\section{Future Research and Limitations}

This purpose of this study was to gain insight into the lives, habits, and choices of young adults who grew up without television, to then generate questions for future research. Overall, results suggest that youth who grew up without television may have improved health outcomes, engage in creative hobbies, and have a strong sense of agency. From this information, there are myriad questions to investigate regarding the influence of television or lack of television on youth development. Several questions were noted throughout this paper, including more detailed research comparing health and perhaps academic outcomes of television and nontelevision viewing youth. Similar comparisons could be made regarding academic achievements and job status.

A limitation of the current study can also provide questions for future research. The current study does not address the influence of external factors on tv-free youths' lives, such as parenting style, peers, school and community climate, religious views, or other factors that may have impacted childhood development, and later lifestyle choices. Knowing more about who and what influenced youth, specifically sense of agency, creation, and perhaps sense of self, social comparison, or personal dreams, could help researchers better understand the role of television and other influences in youth development.

Specifically, additional questions should be asked about parenting style. It could be that parents who chose not to have a television in their home also made other intentional child-rearing choices. Perhaps these parents were very supportive or even directive of the child's free time activities, or perhaps they left the child alone to develop or create on his or her own. Parenting style is certainly indicated in the literature as having an impact on child personality and 
behaviors, and this needs to be further investigated, and in relation with the choice to remove television from the home.

Another interesting question is around social comparison or development of social norms. Much research indicates that media has a strong influence on youth standards of beauty, body image, and social status. Further, the media is frequently criticized for promoting or glamorizing risktaking behaviors, or engaging in sex, smoking, alcohol consumption, and violence, and influencing youth attitudes to potentially engage in these behaviors (Fischer, Greitemeyer, Gastenmuller, Vogrincic, \& Sauer, 2011; Grube \& Wallack, 1994; Sargent, Dalton, \& Beach, 2000). As the youth in this group did not watch television, might their image of self, social comparisons, or ideas about social norms be different? Certain behaviors or lack thereof, could be explained by social learning or cultivation theories, among others, and could be avenues for further investigation.

\section{Conclusion}

In sum, this study has provided a glimpse into the lives of youth who grew up without television, and shared a picture of their habits and hobbies as young adults. Additional research is needed to investigate further the source or other major influence on behavior, and to compare their outcomes to those of youth who watch television. With television viewing blamed for so many negative outcomes, this is important research that could help parents, teachers, and leisure providers consider they role television does or should play in youths lives.

\section{References}

Bandura, A. (2006). Toward a psychology of human agency. Perspectives on Psychological Science, 1(2), 164-180.

Bloom B.S. (1956). Taxonomy of Educational Objectives, Handbook I: The Cognitive Domain. New York: David McKay Co Inc.

Boynton-Jarrett, R., Thomas, T.N., Peterson, K.E., Wiecha, J., Sobol, A.M., Gortmaker, S.L. (2003). Impact of television viewing patterns on fruit and vegetable consumption among adolescents. Pediatrics. 112: 1321-1326.

Brock, B. (2007). Living outside the box: TV-free families share their secrets. Eastern Washington University Press.

Carson, V., \& Janssen, I. (2012). The mediating effects of dietary habits on the relationship between television viewing and body mass index among youth. Pediatric Obesity, 75$)$, 391398.

CDC/National Center for Health Statistics. (2010). Retrieved from http://www.cdc.gov/nchs/hdi.htm.

Charmez, K. (2006). Constructing grounded theory: A practical guide through qualitative analysis. Thousand Oaks, CA: Sage.

Child Trends Data Bank. (2009). Monitoring the Future, 1991-2011. Retrieved from www.childtrendsdatabank.org 
Epstein, L.H., Roemmich, J.N., Robinson, J.L., Paluch, R.A., Winiewicz, D.D., Fuerch, J.H., Robinson, T.N. (2008). A randomized trial of the effects of reducing television viewing and computer use on body mass index in young children. JAMA Pediatrics, 162(3), 239-245.

Fischer, P., Greitemeyer, T., Kastenmüller, A., Vogrincic, C., \& Sauer, A. (2011). The effects of risk-glorifying media exposure on risk-positive cognitions, emotions, and behaviors: A metaanalytic review. Psychological Bulletin, 1373), 367-390.

Gantz, W., Schwartz, N., Angelini, J.R., Rideout, V. (2007). Food for thought: Television food advertising to children in the United States. A Kaiser Family Foundation Report.

Grube, J.W., \& Wallack, L. (1994). Television beer advertising and drinking knowledge, beliefs, and intentions among schoolchildren. American Journal of Public Health, 84, 254-259.

Gorley, T., Marshal, S.J., \& Biddle, S.J.H. (2004). Couch kids: Correlates of television viewing among youth. International Journal of Behavioral Medicine, 11(3), 152-163.

Krathwohl, D.R. (2002). A revision of Bloom's taxonomy: An overview. Theory into Practice, 41(4), 211-218.

Kubey, R. \& Csikszentmihalyi, M. (1990). Television and the quality of life: How viewing shapes everyday experience. Lawrence Erlbaum Associates, Inc. Hillsdale, NJ.

Neilson. (2009). TV viewing among kids at an 8-year high. Nielson Newswire: Media and Entertainment.

Sargent, J.D., Dalton, M.A., \& Beach, M. (2000). Exposure to cigarette promotions and smoking uptake in adolescents: evidence of a dose-response relation. Tobacco Control, 9, 163-168.

Strauss, A., \& Corbin, J. (n.d). Grounded theory methodology: An overview. In Strategies of Inquiry, p. 273-285.

Taveras, E.M., Sandora, T.J., Shih, M., Ross-Degnan, D., Goldmann, D.A., Gillman, M.W. (2006). The association of television and video viewing with fast food intake by preschool-age children. Obesity, 14(11), 2034-2041.

(c) Copyright of Journal of Youth Development $~$ Bridging Research and Practice. Content may not be copied or emailed to multiple sites or posted to a listserv without copyright holder's express written permission. Contact Editor at: patricia.dawson@oregonstate.edu for details. However, users may print, download or email articles for individual use.

ISSN 2325-4009 (Print); ISSN 2325-4017 (Online) 